\title{
Research on the Relationship between Financial Development and Economic Growth in China: An Empirical Analysis based on Panel Smooth Transition Regression Model
}

\author{
Li-ting Fang* \\ Department of Statistics, School of Economics and Management, Fuzhou University, Fuzhou \\ 350116, P.R. of China
}

\begin{abstract}
In this paper, the panel smooth transition regression model was used to analyze the relationship between financial development and economic growth empirically. The paper mainly studied the effects of proportion of total loans of regional financial institutions in GDP on the output elasticity of capital, labor output elasticity and returns of scale. The empirical results show the level of financial development has a nonlinear diminishing relationship with the capital output elasticity, and has a nonlinear increasing relationship with labor output elasticity and returns of scale.

Index Terms - Panel smooth transition regression model; Financial development; Economic growth
\end{abstract}

\section{Introduction}

Both China's economy and finance have been developed rapidly since the reform and its opening up. The financial industry has undergone tremendous changes with the economic .China's financial sector is almost zero at the beginning of the reform and its opening up. Financial types are greatly enriched now, and there is a substantial increase in the total amount of financial assets. Finance has become an important means of government macroeconomic regulation and optimizing allocation of social resources. Economy is showing the characteristics of financialization increasingly .So modern finance plays a vital role in economic growth. In this context, the impact of finance development on economic growth is common concerned by domestic and foreign scholars. Therefore, to study the relationship between financial development and economic growth in China has important practical significance.

Financial development and economic growth has been the focus of economists' theoretical and empirical research. Schumpeter proposed the theory that economic growth was promoted by financial development firstly. Later scholars have done a lot of studies about the relationship between the two. Arestis and Demetriades (1997) found that, development of German bank affected economic growth. But there was insufficient evidence to show the effect of financial intermediation on economic growth in Unite States. Bell and Rousseau (2001) found that, financial structure, economic system, the level of economic development and its stage system could affect the role played by financial development on economic growth. Khan and Senhadji (2003) found that some banks' development indicators played a negligible role on economic growth. Beck and Levine (2004) stated that banks increased the return of savings rate through the allocation of resources, but the development of bank may reduce the savings rate. Choong and Lim (2009) used endogenous growth model to analyze the effect of financial development and FDI on enhancing economic growth in Malaysia. Shi (2003) based on the Cobb-Douglas production function analysis framework, found that there was a two-way causal relationship between financial development and economic growth and that financial development had a significant role in promoting economic growth. Wang (2005) used the error correction model and Granger causality test, and found the existence of a close relationship between financial development and economic growth in the region empirically. Ran (2006) based on Chinese provincial panel data of China's east and west region, used unit root test, co-integration test and error correction model, researched the short and long term relationship between eastern and western financial development and economic growth, and found the significantly different relationship between eastern and western financial development and economic growth. Therefore, it can be considered that the relationship between financial development and economic growth may not be stable under different conditions. Liu (2006) constructed different indicators to measure the financial structure, used dynamic panel data model of financial structure and economic growth and GMM estimation method, and obtained the conclusion that the stock market had a high proportion in countries with high per capita GDP. Yuan ( 2007 ) researched the relationship between China's financial development and efficiency of economic growth by using stochastic frontier model based on Chinese provincial panel data from 1978 to 2004. Chen (2008) made an empirical analysis and found a significant positive correlation between Chinese financial development and economic growth based on the data from 1952 to 2007. Fan (2011) studied the relationship between Chinese financial development and economic growth by using quarterly data from 1993 to 2002, which concluded that there is the limited impact of the financial intermediary development on economic development. Li (2012) used the unit root test, co-integration and Granger causality test to research the relationship between 
financial development and economic growth of Hainan Province in China. The empirical result showed that, there was the long-run equilibrium relationship between financial related ratios and per capita GDP, and economic growth was affected and promoted by financial development to some extent.

\section{Inspection and Estimate of Panel Smooth Transition Regression Model}

To reveal the nonlinear relationship which may be existed between the variables, a panel smooth transition regression model (PSTR) proposed by Gonzalez et al $(2004,2005)$ is used in this paper. The model is the further expansion of panel threshold regression model (PTR).Because PSTR model is able to characterize section heterogeneity of panel data, it is often concerned by researchers.

The basic PSTR model with two extreme regimes is defined as :

$$
y_{i t}=\mu_{i}+\beta_{0}^{\prime} x_{i t}+\beta_{1}^{\prime} x_{i t} g\left(q_{i t} ; \gamma, c\right)+\varepsilon_{i t}
$$

Where

$i=1,2, \cdots \cdots, N \quad t=1,2, \cdots \cdots, T \quad, \quad g\left(q_{i t} ; \gamma, c\right)$ is a transition function with the values changing from 0 to 1 continuously, $q_{i t}$ is the observable variable which is also called transition variables, parameter $\gamma$ is called the slope coefficient or smoothing parameter which determines the transition rate, $c$ is the positional parameter where the transition occurs.

At present, $g\left(q_{i t} ; \gamma, c\right)$ is usually in the form of the following logistic specification:

$$
g\left(q_{i t} ; \gamma, c\right)=\left(1+\exp \left(-\gamma \prod_{j=1}^{m}\left(q_{i t}-c_{j}\right)\right)\right)^{-1}
$$

where $c_{1} \leq c_{2} \leq \cdots \leq c_{m}, \gamma>0$. When $m=1$ and the transition function $g(\cdot)=0$, the corresponding model (1) is called the low regime. While $g(\cdot)=1$, the corresponding model (1) is called the high regime. The model (1) implies that the two extreme regimes are associated with low and high values of $q_{i t}$ with a single monotonic transition of the coefficients from $\beta_{0}$ to $\beta_{0}+\beta_{1}$ as $q_{i t}$ increases with the parameter $c$ as the centre.

Application of PSTR model must solve some problems which include the nonlinear test of the model, determination of parameters in transition function and estimation of parameters in the model. we used the auxiliary equation proposed by Gonzalez (2005) for testing in the paper. If the test is passed ,that is, heterogeneity exists in the model, then the PSTR model estimate is considered. As we known, the ordinary least squares (OLS) method is usually used for the linear model, while PSTR model in this paper is a non-linear model and the main problem is the nuisance parameter contained in the model. Because some parameters which can not be recognized could be pre-determined, and then the nonlinear model is converted into a linear model, PSTR model is a condition linear parametric model. The paper used nonlinear least squares (NLS) to estimate model after eliminating the fixed effects of the panel model. The initial value of $\gamma$ and $c$ in the transition function is often determined by a grid search method or simulannealbnd algorithm. In the article, we use the simulannealbnd algorithm.

\section{Empirical Research}

\section{A. Model Determination}

Labor and capital are the two main factors to decide the level of total economic output in neoclassical growth theory, technological advances also have exogenous effect on output. The mathematical expression of the neoclassical production function is set as follows:

$$
Y=F(K, L, A)
$$

where $Y$ refers to the level of output with $K, L$ and $A$ denoting the capital stock, labor and technology. Considering the form of the production function, Cobb-Douglas production function is more commonly used in the theoretical and empirical analysis. Without considering the technology, Expression of Cobb - Douglas production function is:

$$
F(K, L)=K^{\alpha} L^{\beta}
$$

where $\alpha$ and $\beta$ denote the output elasticity of capital and labor, while the sum of $\alpha$ and $\beta$ denotes returns to scale. That their sum is greater than one indicates the increasing returns to scale, and less than one indicates the decreasing returns to scale, while the sum equals to one means a constant returns to scale.

To take the logarithm on both sides of Cobb - Douglas production as follows:

$$
\ln Y=\alpha \ln K+\beta \ln L
$$

To set $\ln Y=y, \ln K=k, \ln L=l$, So the model is simplified as follows:

$$
y=\alpha k+\beta l
$$

Since the above traditional linear model often ignores the internal structure change between economic variables, PSTR model is a common nonlinear model which is mainly used to analyze economic phenomenon with the occurrence of regime switching. The estimation results are often more able to describe the contained economic law. Therefore, considering the widely existence of China's financial uneven development in various regions and the nonlinear relation between economic variables, this paper studies the relationship between financial development and economic growth from the angle of cross section. Based on Cobb Douglas production function, 
PSTR model with the financial development $\left(q_{i t}\right)$ index as transformation variables is set as follows:

$$
y_{i t}=\mu_{i}+\left(\alpha k_{i t}+\beta l_{i t}\right)+\left(\alpha^{\prime} k_{i t}+\beta^{\prime} l_{i t}\right) g\left(q_{i t} ; \gamma, c\right)+\varepsilon_{i t}
$$

In the above model, the transition function is taken the form of logical function, $(\alpha, \beta)$ refers to the parameters of the linear part, and $\left(\alpha^{\prime}, \beta^{\prime}\right)$ refers to the parameters of the nonlinear part. Therefore, we can get the total output elasticity of capital and labor:

$$
\begin{aligned}
& \alpha\left(q_{i t}\right)=\frac{\partial y_{i t}}{\partial k_{i t}}=\alpha+\alpha^{\prime} g\left(q_{i t} ; \gamma, c\right), \\
& \beta\left(q_{i t}\right)=\frac{\partial y_{i t}}{\partial l_{i t}}=\beta+\beta^{\prime} g\left(q_{i t} ; \gamma, c\right),
\end{aligned}
$$

In the above equation, $\alpha\left(q_{i t}\right)$ and $\beta\left(q_{i t}\right)$ are functions of transition variables, and the sum of $\alpha\left(q_{i t}\right)$ and $\beta\left(q_{i t}\right)$ denotes returns to scale.

\section{B. Index Selection and Data Processing}

The research object of this paper is the panel data of 31 provinces from 1999 to 2013 in China. In order to estimating the empirical model above, the data of the total output, capital stock, labor and financial development all must be known. Considering the specific meaning of variables and the availability of data, index selection and the necessary processing for the variables in empirical analysis are needed as follows.

First, GDP with the constant price in each area is used as a measure of total output. In order to eliminate the impact of price, the year 1999 is set as the base period. By using the GDP growth index in each year and GDP in 1999 in various regions, GDP with the constant price can be obtained by numerical calculation. In this paper, GDP with the constant price is taken to represent the total output $Y$. Secondly, the whole society employment in each region is taken as the measuring index of labor. Thirdly, ratio of RMB loans and GDP in financial institutions in each area is taken as a index of financial development. Finally, a fixed capital stock of each area is taken as an alternative variable of capital stock. As in many literatures, this paper uses the perpetual inventory method for the estimation of the fixed capital stock in each region. In order to eliminate the impact of price, the price index of fixed assets investment in each year is used for the deflator to fixed assets investment before the calculation of the fixed capital stock. Finally, all data used is from "China Statistical Yearbook" in each year.

\section{Results and Analysis of Model Estimation}

According the theoretical approach introduced above, we must test section heterogeneous of panel data firstly. According to the test results, the null hypothesis of linear model is rejected significantly. This shows that panel data has clear cross-sectional heterogeneity. So the set model can well capture the non-linear characteristics between variables. Thus to use the index of financial development as the transition variable for estimation of PSTR model is appropriate. In this paper, the $\mathrm{P}$ value in the table is on the 5\% significant level. Secondly, the method of the auxiliary equation is used to determine the number of order $m$ in transition function, and the optimal order number is one.

Then the simulannealbnd algorithm is used to determine the initial values of the slope coefficients and the position parameters .Seen From table 1, the optimal initial value of the parameters in transition function is $(6.6652,2.516)$.It means that the smooth transition of financial development index occurs near the value of 6.6652. After the determination of the initial value of slope coefficients and the location parameters, ordinary least squares method and the nonlinear least square method are used for the estimation of parameters in the model. The results are shown in table 1 , table 2 and figure 1 .

Table 1 The initial values and estimation result of $\gamma$ and $c$

\begin{tabular}{|c|c|c|c|c|c|}
\hline Parameter & Initial Value & Estimate & Standard Error & T value & P value \\
\hline$\gamma$ & 6.665 & 8.2508 & 2.3809 & 3.465 & 0.000 \\
\hline$c$ & 2.516 & 2.4932 & 0.0450 & 55.40 & 0 \\
\hline
\end{tabular}

Table 2 Estimation result of model

\begin{tabular}{|c|c|c|c|c|}
\hline Parameter & Estimate & Standard Error & T value & P value \\
\hline$\alpha$ & 0.71251 & 0.0096482 & 73.849 & 0 \\
\hline$\beta$ & -0.03394 & 0.012843 & -2.6428 & 0.0085725 \\
\hline$\alpha^{\prime}$ & -0.2737 & 0.016428 & -16.661 & 0 \\
\hline$\beta^{\prime}$ & 0.30241 & 0.020403 & 14.822 & 0 \\
\hline$F_{\text {value }}$ & \multicolumn{5}{|c|}{396.01} \\
\hline $\mathrm{P}_{\text {value }}$ & \multicolumn{5}{|c|}{$0.97414(0.97175)$} \\
\hline$R_{\left(\bar{R}^{2}\right)}^{2}$ & \multicolumn{5}{|c}{} \\
\hline
\end{tabular}

According to the above estimation results, it can be found that the whole model is statistically significant and the model fitting effect is quite good seen from the model decision coefficient. The estimation results show that the estimation value of smoothing parameter is 8.2508 , indicating that the model transition speed is slow and the transition between different mechanism is smooth. All the coefficients in the linear part and nonlinear part of model are significant, in which the parameter value of the capital coefficient in linear part is positive and negative in the nonlinear part. In absolute terms, the value in the linear part is far greater than in the nonlinear part. This shows that the capital accumulation has the significant positive linear effect and nonlinear negative impact on economic growth, and the linear effect is dominant. In the integrated view, the effect of capital accumulation on economic growth is positive. On the other hand, labor factor 
has a significantly negative but weak linear effect on economic growth. Labor coefficient in the nonlinear part is significantly positive, and its absolute value is greater than the parameter value in the linear part. It shows that labor factor also has significant stronger nonlinear positive influence on economic growth. In addition, there is only one location parameter in mode (1). This shows that the threshold value of the influence of the proportion of total loans in RMB in financial institutions and GDP on economic growth is 2.516 . When the proportion is more than 2.516, the trend of model is high system. The smooth transition of the output elasticity of capital and labor would be occurring between the high and low system with the changes of transition variable value. The change curves of the model coefficients and transfer function diagram are showed in Figure 1.Seen from the diagram, the output elasticity of capital is basically unchanged firstly, then suddenly falls to an inflection point sharply, and tends to be stable to a certain extent finally with the increasing of the proportion of RMB loans in financial institutions in each area accounted for GDP. In a word, there is a decreasing nonlinear relationship between the degree of financial development in every region and capital output elasticity and an increasing nonlinear relationship between the degree of financial development and output elasticity of labor or the returns to scale.
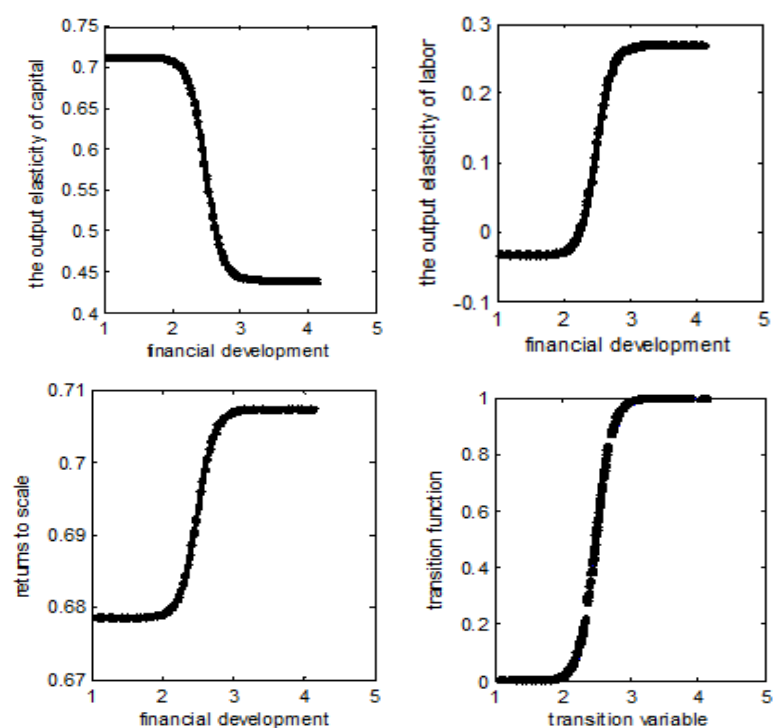

Fig 1 Influence of Financial development on the output elasticity of capital and labor and returns to scale and the transition function diagram

\section{Conclusion}

This paper uses the panel smooth transition regression model for empirical analysis of the relationship between financial development level in different regions and economic growth based on the panel data in China from 1999 to 2013 .The paper mainly analyzes the effect of the proportion of the RMB loans of financial institutions in each area accounted for GDP on the output elasticity of capital and labor and returns to scale of economic growth. The empirical results show that the labor factor has a significant negative linear effect and the stronger nonlinear positive influence on economic growth. The capital factor has a remarkable positive linear effect and negative nonlinear influence on economic growth and the linear effect is dominant with the variation of the proportion of RMB loans of financial institutions in each area accounted for GDP. It also shows that the degree of financial development in each area is negatively related to the output elasticity of capital and is positively related to the output elasticity of labor and the returns to scale.

In short, PSTR model is more general on setting the form of the equation when we need to investigate the linear and nonlinear relationship between economic variables at the same time. Comparing with the traditional parallel data fixed effect model, heterogeneity in cross-section unit can be better captured, and it also can better reflect the nonlinear relationship between economic variables.

\section{References}

[1] R.G. King, and R. Levine, "Finance and growth: Schumpeter might be right", The Quarterly Journal of Economics, vol.108, pp.717-738,1993.

[2] R.G. King, and R. Levine, "Finance, entrepreneurship and growth: theory and evidence", Journal of Monetary economics, vol.32, pp. 513$542,1993$.

[3] R. Levine, "Law, Finance and economic growth", Journal of Financial Intermediation, vol.8,pp. 8-35,1999.

[4] P. Arestis, and P. Demetriades, "Financial development and economic growth: assessing the evidence", Economic Journal ,1997.

[5] Acemoglu, and F. Zilibotti, "Was Prometheus Unbound by Chance? Risk, Diversification, and Growth", Journal of Political Economy, vol.105, no. 4, 709-751, 1997.

[6] Y. Shi, and Z. Wu, "An Empirical Analysis of Financial Sector Development and Economic Growth in China", Forecasting, vol.22,no.4,pp.1-5,2003.(in Chinese)

[7] J. Wang, "Empirical research on Regional Financial Development and Regional Economic Growth in China ", Finance \& Trade Economics, no.10,pp.23-25,2005. (in Chinese)

[8] G. Ran, and J. Li, "Study on the Regional Difference in Relation of Financial Development with Economic Growth in China-Based on the Panel Data in Eastern and Western ", China Soft Science, no.2,pp. 102110,2006. (in Chinese)

[9] J. Li, et al, "Study on the Relationship between Financia 1Development and Economic Growth in Hainan in China ", Contemporary Economics, no.3,pp.78-79,2012. (in Chinese)

[10] H. Liu, and H. Zheng, "An Empirical Study on the Relationship between Financial Structure and Economic Growth in the Eastern Asian Countries", Studies of International Finance,no.5,pp.50-57, 2006. (in Chinese)

[11] Y. Yuan, and X. Cao, "Empirical Research on the Relationship between Financial Development and Efficiency of Economic Growth", Statistical Research, vol.24,no.5,pp.60-66,2007. (in Chinese)

[12] Fan, "A Positive Study on the Relationship between Financial Development and Economic Growth Based on the China", Nanjing Journal of Social Sciences,no.1,pp.29-35,2011. (in Chinese)

[13] H. Zhou, and Y. Zhong, "Research on Relationship between Chinese Financial Intermediary Development and Regional Economic Growth", Journal of Financial Research, no.6, pp.130-137,2004. (in Chinese) 